\title{
A General Equilibrium Analysis of Check Float*
}

\author{
James McAndrews \\ Research Department \\ Federal Reserve Bank of New York \\ 33 Liberty Street \\ New York, NY 10045-0001 \\ jamie.mcandrews@ny.frb.org \\ William Roberds \\ Research Department \\ Federal Reserve Bank of Atlanta \\ 104 Marietta Street, N.W. \\ Atlanta, GA 30303-2713 \\ william.roberds@atl.frb.org \\ First Draft: April, 1997 \\ Last Revised: August, 1999
}

\begin{abstract}
Households and businesses in the U.S. prefer to use check payment over less costly, electronic means of payment. Earlier studies have focused on check "float," i.e., the time lag between receipt and clearing, as a potential explanation for the continued popularity of checks. An underlying assumption of these studies is that check float operates as a pure transfer from payee to payor.

We construct a simple general equilibrium model in which payments are made by check. In general equilibrium, check float need not act as a transfer. If float can be priced into market transactions, then it has no effect on equilibrium allocations. If float is not priced into market transactions, then it acts as distorting tax. Consistent with earlier studies, we show that float can also lead to inefficiencies if banks engage in costly activities designed to accelerate check presentment.

Our analysis is consistent with view that float is a significant factor behind the continued popularity of check payment. Our analysis also consistent with recent data that indicate that the average value of float (per check) is small.
\end{abstract}

Journal of Economic Literature Classification Codes: E58, G21, G28.

\footnotetext{
* The authors thank Zsolt Becsi and Scott Freeman for helpful discussions leading up to this paper. We have also benefited from comments by John Bryant, Jerry Dwyer, Bob Eisenbeis, Marco Espinosa, Steve Russell, Bruce Smith, participants in seminars held at the Federal Reserve Bank of Cleveland, the Office of the Comptroller of the Currency, and the University of Illinois, and two anonymous referees, with the usual disclaimer. The opinions expressed in this paper are those of the authors, and not necessarily those of the Federal Reserve Banks of New York or Atlanta, or of the Federal Reserve System.
} 


\section{A General Equilibrium Analysis of Check Float}

\section{INTRODUCTION}

Payment by check is by far the most popular form of noncash payment in the U.S. In 1996, 65 billion payments or roughly 74 percent of noncash payments were made by check. The value of all checks written in 1996 was $\$ 75$ trillion, comprising about 87 percent of "small-value" or "retail" non-cash payments. ${ }^{1}$

While popularity of check payment is beyond dispute, its efficiency is not. Wells $(1996,5)$ estimates that the average cost of a payment by check averages roughly $\$ 1.60$ more than the cost of a payment made electronically via the Fed's automated clearinghouse $(\mathrm{ACH})$ system- $\$ 2.90$ per payment by check vs. $\$ 1.30$ per payment by ACH in 1993 dollars, when the costs of all parties are taken into account. ${ }^{2}$ Yet despite this cost disparity and despite increased opportunities to use $\mathrm{ACH}$ and other electronic forms of payment, checks have remained the predominant form of noncash payment in the U.S. And by some measures, the popularity of check payment has actually increased in recent years. $^{3}$

Does this continued use of an apparently inefficient means of payment constitute a market failure? According to an influential study (Humphrey and Berger 1990), the answer to this question is "yes." Humphrey and Berger identify check float as a potential cause of market failure. Float is defined as the time lag between the receipt of a check as payment and its clearing. Until the check clears, the writer of the check has access to the

\footnotetext{
${ }^{1}$ Figures are from Bank for International Settlements (1997). "Small-value" payments exclude "largevalue" payments made over the Fedwire and CHIPS networks.

${ }^{2}$ The estimates by Wells are necessarily imprecise, since in U.S case, little is known about certain types of check processing costs. Flatraaker and Robinson $(1995,324)$ report the results of a 1994 Norwegian survey of costs for various payment instruments. They find the average cost (at the bank level) of a check payment to be roughly $\$ 2.15$, whereas the average cost of an $\mathrm{ACH}-$ like payment is put at $\$ .92$. The implied electronic payment/check cost ratio (.43) is very similar to that reported by Wells.
} 


\section{A General Equilibrium Analysis of Check Float}

funds and can earn interest on these funds. Ceteris paribus, the presence of float leads to a transfer of interest income from the receiver of the check to the check writer. A sufficiently large transfer could lead to a preference for using checks over electronic methods of payment which are not subject to float. Using 1987 data, Humphrey and Berger estimate that the average amount of the float transfer more than compensates for the cost advantage of $\mathrm{ACH}$ over checks.

Humphrey and Berger's characterization of check float is challenged by Wells (1996). Using 1993 data, Wells estimates that the average value of check float has fallen quite dramatically in recent years, i.e., from $\$ 1.04$ per check in 1987 to $\$ .09$ per check in 1993. The decrease in the average float value has resulted from both reductions in check processing lags and in nominal short-term interest rates. Since the average value of float is small relative to the differential in average cost between payment by check and payment by $\mathrm{ACH}$, Wells argues that check float cannot be a source of "market failure" in the market for payments.

A potential limitation of the analysis in this area has been the partial-equilibrium nature of its theoretical underpinnings. For example, both Humphrey and Berger (1990, 51) and Wells $(1996,4)$ characterize float as a pure transfer of income from the check receiver to check writer. As noted above, this is true in a partial equilibrium sense. In general equilibrium, however, it stands to reason that beneficiaries of float will use their additional income to income to bid up prices of the goods they wish to purchase, causing prices to adjust in general equilibrium, and potentially leading to distortions in the absence of complete markets.

\footnotetext{
${ }^{3}$ See Humphrey, Pulley, and Vesala (1996).
} 


\section{A General Equilibrium Analysis of Check Float}

Below, we present a model that allows for examination of the costs of float in a general equilibrium environment. The model is an adaptation of Freeman's (1996a) model of banknote issue. While the model is highly stylized, it incorporates some relevant features of the U.S. banking and payments systems. Our findings are as follows.

First, if float is sufficiently widespread (though not universal) throughout the economy, then it may have no effect on equilibrium allocations. That is, the income effects of float may be entirely offset by substitution effects.

Second, a combination of par check valuation and differential clearing lags can cause float to have allocational consequences. In this case, float inflates the relative prices of goods which are purchased with checks drawn on remote locations. The effect is a distortion of relative prices rather than a transfer.

Third, we show that if costs must be incurred in order to reduce float or "accelerate presentment," then presence of such costs can result in welfare losses when banks cannot cooperatively agree on an allocation of float benefits. This result is consistent with the views advanced by Humphrey and Berger (1990) and Lacker (1997), that such activities are socially costly.

Finally, we argue that the second and third results, when taken together, imply that float may be a significant factor behind the continued use of checks. If no one were a net beneficiary of check float, then the third result implies that there would be an incentive for check users and their banks to cooperatively agree to give up the benefits of float. This could be done by altering rules for clearing checks (as has been done in other countries) or by adoption of a different payment technology. On the other hand, as long as the marginal value of float is high for some check writers, as is implied by our second result, 


\section{A General Equilibrium Analysis of Check Float}

securing such a cooperative agreement would be more difficult, even though the value of float might appear inconsequential when averaged across all checks. This view is consistent with the original Humphrey-Berger (1990) view that float is an important motivation for the continued use of checks. However, this view is also consistent with Wells' (1996) finding that the average value of float is small.

\section{THE MODEL}

\subsection{Institutional Environment}

A formal model of check float requires certain key ingredients. First, the model must contain an environment in which economic agents have an incentive to trade, i.e., an "Edgeworth box." Second, since changes in float by definition involve changes in the allocation of nominal interest income, the model should incorporate a role for money, i.e., prices should be allowed to vary endogenously in response to changes in monetary policy or in the design of the payment system. Third, there should be a role for "checks," i.e., transfers of inside money or privately issued debt, as a medium of exchange. Fourth, in order to model agents' incentive to capture the benefits of float, the model should provide a role for both non-interest bearing government debt or outside money, and for interestbearing assets such as government bonds.

To produce a model with these features we will adapt Freeman's (1996a) model, in which spatially separated agents make payments using privately issued debt. By employing this model, we are following the tradition of the monetary literature, in which a 


\section{A General Equilibrium Analysis of Check Float}

spatial separation friction is taken as a convenient metaphor for other, potentially more complicated frictions that could lead to the use of money as a medium of exchange. ${ }^{4}$

There are a number of formal distinctions between our setup and Freeman's. These distinctions result from our placing certain institutional constraints on the model environment. The constraints are intended to mimic some noteworthy features of U.S. banking and payments institutions, particularly as they apply to the use of checks as a payments medium.

First, as in Freeman's model, agents in our model will make payments using inside money. However, in our model, only banks may create inside money, and inside money cannot be issued in circulating (banknote) form. Instead, inside money can only be created as demand deposits at banks. When a demand deposit claim is transferred in order to make a purchase, then the transfer must be cleared through the banking system in order for the purchase to be valid. This restriction is designed to mimic historical restrictions on private banknote issue.

Second, outside money serves a special role in our model. That is, outside money will be the only acceptable medium for settlement of interbank transactions, when the transactions do not take place through a private arrangement. While settlement in outside money is not a legal requirement in the U.S., it is common expectation and a de facto requirement that such transactions be settled in outside funds. ${ }^{5}$ This requirement will not hold for interbank transactions made through a private clearing arrangement.

\footnotetext{
${ }^{4}$ The spatial separation restrictions are basically a prohibition on the issue of certain types of debt, so that purchases cannot be paid for with simple IOUs. Some recent papers which use spatial-separation monetary models to analyze payments issues include Freeman (1996b), Green (1997), and Lacker (1997b).

${ }^{5}$ In models where banks can hold risky portfolios, settlement on the books of a central bank (i.e., in outside funds) can be value-enhancing if settlement arrangements allow for some risk-shifting from commercial
} 
Third, we take as a legal requirement that checks must be honored at par value in interbank exchange. More specifically, a paying bank must honor a check drawn on one of its accounts at par, or face value. This restriction has applied to virtually all interbank exchanges in the U.S. since the 1920s. Before that time, it was common for paying banks to discount checks presented by banks from outside the local banking market, a practice known as "nonpar banking."

Fourth, in keeping with U.S. banking history, we assume that banking markets are "geographically dispersed," and that banks are prohibited from branching into all banking markets. Further, banks cannot form private clearing organizations across all banking markets.

Finally, Freeman (1996a) assumes that clearing across locations is costless. In Section 5 , we explore the consequences of allowing agents the option of costly accelerated check presentment. We assume that all such costs are borne by the bank (and ultimately the depositor) that is presenting the check for payment. This is again consistent with current U.S. practice.

\subsection{Preferences, Endowments, and Technology}

Following Freeman (1996a), the economy takes place on $I+1$ isolated locations known as "islands," where $I$ is a large, even number. The first $I$ islands are each inhabited by a large number of two-period lived people. On each island, $N$ new people are born in each period $t \geq 1$. In the first period there is a group of $N$ people (the "initial old") who live for only one period. Each person born on one of these islands is endowed when young

\footnotetext{
banks to the central bank. This incentive is modeled by Emmons (1995) and Kahn and Roberds (1998). This incentive cannot be captured in the setup described below, since banks hold riskless portfolios.

${ }^{6}$ Duprey and Nelson (1986) chronicle the transition from nonpar to par payment of checks.
} 


\section{A General Equilibrium Analysis of Check Float}

with $y$ units of a good that is unique to that island. The good is not transportable across islands, and is nonstorable in the sense that it vanishes at the end of the period if not consumed. People wishing to make transactions will journey to other islands in order to obtain their desired consumption good.

The first $I$ islands are split into "archipelagoes." An archipelago will define a local banking market. Each archipelago contains an equal number of two types of islands, “debtor" and "creditor" islands (see Figure 1).

People born on debtor islands ("debtors") wish to consume some of their own endowment good and also the good of a creditor island when young, and nothing when old. On every debtor island, some debtors may want to consume creditor goods found on creditor islands within their own archipelago, and others may wish to consume creditor goods found on creditor islands of other archipelagoes. The utility of a debtor is given by $v\left(c_{t}, d_{t}\right)$, where $c_{t}$ represents the debtor's consumption of the creditor good, and $d_{t}$ the consumption of their own endowment good.

People born on creditor islands ("creditors") wish to consume some of their own endowment good while young, and also wish to consume a good found on a particular debtor island while old. In contrast to debtors, creditors never wish to buy goods from outside their own archipelago. Creditors also cannot directly consume debtors' endowment goods. A debtor's endowment must first be transformed by a production process (described below) before it can be consumed by creditors. A creditor's utility is given by $u\left(C_{t}, D_{t+1}\right)$, where $D_{t+1}$ represents the creditor's consumption of the debtor good, and $C_{t}$ represents the consumption of their own endowment good. The utility functions of both 


\section{A General Equilibrium Analysis of Check Float}

the debtors and creditors are sufficiently well-behaved so that interior optima obtain for both types. $^{7}$

The $I+1^{\text {st }}$ island is known as the "central island." On the central island there are commercial banks ("banks"), a central bank, and a government. Banks are infinitely lived, and their utility is given by $\sum_{t=0}^{\infty} \beta^{t} e_{t}$ where $e_{t}$ represents period $t$ consumption and $\beta$ is a discount factor. Banks are endowed with technologies, described in more detail below, that allow them to keep perfect records and "clear" payments across islands and archipelagoes. However, due to branching restrictions, not every bank can offer banking services to every archipelago. In particular, each bank can offer banking services to ("have a branch on") only a fraction of the archipelagoes. Bank branches are also endowed with a production technology that can transform debtors' endowment goods into goods that can be consumed by creditors. The production process converts one unit of endowment into one unit of a consumption good.

In addition to record-keeping and production technologies, banks are endowed with an initial stock of one-period-maturity government bonds $B_{0}$ and an initial stock of central-bank issued fiat money $M_{0}$. Fiat money cannot be counterfeited, is unbacked, and can be costlessly exchanged. Fiat money is "intrinsically useless," but as discussed above it has a special function in settlement of interbank obligations. Government debt has the same properties as fiat money, with two distinctions. First, debt pays a gross nominal interest rate $R_{t}$ per period. Second, debt cannot be used to settle interbank obligations.

\footnotetext{
${ }^{7}$ To reduce notational clutter, all quantities are per capita.
} 
The initial old creditors on the creditor islands are endowed with claims that aggregate to $M_{0}+B_{0}$, the sum of the initial assets owned by the banks.

The stock of outstanding government debt is financed via seignorage. In steady state, the central bank purchases sufficient government bonds in each period so that the stock of outside money expands at a constant rate $\mu$ per period. Assuming that the government runs a deficit net-of-interest $G_{t}$, its budget constraint is given by

$$
B_{t}=R_{t} B_{t-1}+G_{t}-\left(M_{t}-M_{t-1}\right)
$$

If $G_{t}$ is not too large and grows at a rate $\mu$ in steady state, (1) can be solved forward in the usual way (see e.g., Sargent 1987) to yield

$$
B_{t}=\frac{(1+\mu)^{t}}{r-\mu}\left(\mu M_{0}-(1+\mu) G_{0}\right)
$$

where in steady state $R_{t}=R>1$, and $r=R-1>\mu{ }^{8}$ In steady state, the government budget is balanced in a net-present-value sense, and the constant ratio of money to bonds is given by

$$
\frac{M_{t}}{B_{t}}=\frac{(r-\mu) M_{0}}{\mu M_{0}-(1+\mu) G_{0}}
$$

In what follows, we will restrict our attention to the special case where the government budget is balanced net of interest, implying $G_{t}=0$ and a steady-state money-bond ratio given by

$$
\frac{M_{t}}{B_{t}}=\frac{r-\mu}{\mu}
$$

\footnotetext{
${ }^{8}$ In other words, we are analyzing "dynamically efficient" equilibria in which the real interest rate $(r-\mu)$ exceeds the growth rate of the economy (zero). For recent analyses of related models which consider dynamically inefficient equilibria see, e.g., Espinosa and Russell (1996) or Bullard and Russell (1997).
} 


\section{A General Equilibrium Analysis of Check Float}

\subsection{Trading}

As in Freeman (1996a), each period will consist of three stages. In the first stage, new debtors and creditors are born, receive their endowment good, and consume as much of their endowment good as they desire. In the second stage, young (generation $t$ ) debtors and old (generation $t$-1) creditors travel to other islands in order to consume their desired creditor and debtor goods, respectively. We assume that this travel takes place in a uniform and symmetric fashion, so that there are always the same number of people on every island. In the third stage, debtors and creditors consume the goods of the islands they have traded with.

This setup generates a role for money as a medium of exchange since barter is physically impossible. Outside money alone is insufficient for exchange since the young debtors must travel to remote islands before they have a chance to exchange their endowment good for money. Exchange is possible, however, if young debtors can exchange debt claims for creditor goods and if there is a technology for monitoring and enforcing ("clearing") the transfer of claims. Banks have access to such technology and this allows exchange to occur.

Debtors are legally precluded from paying for their purchases by issuing own IOUs. Instead, debtors must draw on their bank deposits by writing a check. They obtain these deposits by depositing a portion of their endowment good with a local bank. The bank transforms the endowment good into a form that can be consumed by creditors. ${ }^{9} \mathrm{~A}$ check cannot circulate: to be a valid form of payment, it must be cleared and settled

\footnotetext{
${ }^{9}$ For purposes of tractability, we assume that bank branches on debtor islands are willing to buy and sell local goods, so a better name for banks in this environment might be "zaibatsu." We also assume that de-
} 
through the banking system. In order for consumption to occur at the third stage of each period, clearing and settlement must take place at the end of the second stage in each period.

Clearing involves presentation of the check to the bank on which it is drawn. We will initially assume that all checks clear immediately after they are deposited, at a zero operational cost. Banks do not have to physically meet to clear checks. Settlement of a check payment occurs when the paying bank transfers assets of equal value to the collecting bank. Unlike clearing, settlement requires some degree of physical proximity. Settlement can occur in two ways. If the banks involved are members of a local (i.e., archipelago-wide) clearinghouse, then the banks in this clearinghouse can immediately settle on a net basis. In symmetric equilibrium, each bank's net position against all other banks in the clearinghouse will be zero, so no assets need change hands for settlement to occur. Likewise, if the paying bank and the collecting bank are the same bank, or are branches of the same bank, then the transaction is "on-us" so that assets are not exchanged.

Restrictions on branching imply that the banks cannot form economy-wide clearinghouses, however. Instead, a certain fraction $\omega$ of check payments presented to each bank are always from banks outside the "local" clearinghouse. Such payments must be settled by transfer of outside money to the presenting bank. To settle these payments, banks meet on the central island after local settlement has occurred, and settle via exchange of outside funds. Thus, at least some of the debtors' purchases of creditor goods 
will be subject to this settlement constraint, which functions as a sort of cash-in-advance constraint and thereby generates a demand for central bank money. ${ }^{10}$

Young creditors who receive check payments from debtors deposit these checks at a local bank. These creditors draw on their bank funds when they purchase debtor goods during the next period. Since creditors never travel outside their own archipelago, all checks written by creditors are settled either as on-us checks or through a local clearinghouse.

To obtain the outside funds necessary for settlement of debtors' checks, banks trade among themselves (and with the central bank) in a bond market. This market takes place on the central island, at the beginning of the first stage of each period. The banks' demand for outside money in our model results from a combination of two frictions, i.e., spatial separation of banks and legal restrictions on branching, which leave banks with no alternative but to settle some transactions in outside funds. We note that the proportion of transactions $\omega$ settled with outside money need not be large, but only positive, so as to maintain the distinction between money and bonds, and hence a determinate price level. ${ }^{11}$

\section{COMPETITIVE EQUILIBRIUM}

Suppose that there are sufficiently many banks' branches on each island, so that banks are "perfectly competitive" and earn no profits in equilibrium. Banks compete with

\footnotetext{
${ }^{10}$ It would be misleading to characterize the model as a "cash-in-advance" model, however. A key difference between the formulation above and standard representative-agent, cash-in-advance models (e.g., Lucas 1980), is that in our setup, some agents (debtors) are purely by chance subject to a binding "settlement" constraint while others (creditors) are not at all subject to this constraint.

${ }^{11}$ In the actual U.S. economy, demand for outside money as a medium of settlement is small relative to the overall volume of payments. On an average U.S. business day, non-cash payments of roughly $\$ 3$ trillion,
} 
each other by offering depositors interest on deposits held more than one period. ${ }^{12}$ Since equilibrium profits are zero, banks end up paying all profits from their bond portfolio to depositors.

\subsection{Equilibrium without float}

In this case, all checks written during a period $t$ are cleared and settled during period $t$. Interest on deposits therefore accrues to creditors. A fraction $\omega$ of the debtors' checks are written on banks sufficiently distant to require settlement in outside money.

In order to trade, a young debtor must have some funds on deposit at a local bank branch. The bank is willing to take some of the debtor's endowment as a deposit. That is, if the debtor deposits $y-d_{t}$ debtor goods with the bank, the debtor's bank balance $h_{t}$ will be given by

$$
h_{t}=\left(y-d_{t}\right) p_{t}
$$

where $p_{t}$ is the money price of a debtor good on a debtor island. The budget constraint faced by debtors will thus be

$$
y p_{t}=d_{t} p_{t}+h_{t}=d_{t} p_{t}+c_{t} p_{t}^{*}
$$

where $p_{t}^{*}$ is the money price of creditor good on a creditor island. The first-order condition for the debtor's utility maximization problem will be

$$
v_{c} / v_{d}=p_{t}^{*} / p_{t}
$$

where subscripts indicate partial derivatives.

including \$2.5 billion in payments over large-value systems, are settled using less than $\$ 10$ billion in deposits held at the Federal Reserve.

${ }^{12}$ For the moment we rule out any other form of competition among banks. We relax this restriction below. 


\section{A General Equilibrium Analysis of Check Float}

Creditors sell a certain portion of their endowment good while young, receiving check payments in return. In the next period, they use the deposits plus accrued interest to purchase debtor goods. Hence a creditor's budget constraints are defined by

$$
\begin{aligned}
& y_{t} p_{t}^{*}=C_{t} p_{t}^{*}+l_{t} \\
& l_{t}\left(1+\phi_{t}\right)=D_{t+1} p_{t+1}
\end{aligned}
$$

where $l_{t}$ is the period- $t$ bank balance of a young creditor, and $\phi_{t}$ is the (contract) interest rate on deposits. The first-order condition for utility maximization by a creditor is

$$
u_{C} / u_{D}=\left(p_{t}^{*} / p_{t+1}\right)\left(1+\phi_{t}\right)
$$

To solve for the equilibrium allocations, we make use of identities from the representative bank's balance sheet (under the zero-profit condition). Consider the balance sheet of a typical bank at the various stages within a period, where all entries are stated on a per-capita basis:

\section{$<$ Insert Table 1 $>$}

If the bank's books balance at each stage within a period, then we can derive several useful relationships from Table 1. First, from the stage 3 balance sheet it follows that the value of young creditors' deposits equals the value of the bank's outside assets, i.e.,

$$
l_{t}=M_{t}+B_{t}
$$

Since the value of funds paid by debtors for creditor goods equals the value of funds received by creditors, it follows that in equilibrium

$$
h_{t}=l_{t}
$$

Finally, comparing the bank's stage 3 balance sheet at time $t$ to its stage 1 balance sheet at time $t+1$, we obtain 


$$
\left(1+\phi_{t}\right)=\frac{M_{t+1}+B_{t+1}}{M_{t}+B_{t}}=(1+\mu)
$$

Condition (13) says that the interest rate offered by banks to young creditors will be the average return on the bank's portfolio, which in turn represents an average of the return on bonds and the return on money. The bank cannot pay creditors the rate of interest on bonds since it is required to hold some outside money for settlement purposes. To solve for the prices $p_{t}$ and $p_{t}^{*}$, we substitute (11), (12), and (13) into budget constraints (6) and (8) to obtain

$$
\begin{aligned}
& p_{t}=\frac{M_{t}+B_{t}}{y-d_{t}} \\
& p_{t}^{*}=\frac{M_{t}+B_{t}}{c_{t}}
\end{aligned}
$$

Substituting the market prices for debtor and creditor goods into first-order conditions (7) and (10), we obtain the following conditions

$$
\begin{aligned}
& \frac{v_{c}}{v_{d}}=\frac{p_{t}^{*}}{p_{t}}=\frac{y-d_{t}}{c_{t}} \\
& \frac{u_{C}}{u_{D}}=\frac{p_{t}^{*}}{p_{t+1}}\left(1+\phi_{t}\right)=\left(\frac{y-d_{t+1}}{c_{t}}\right)\left(\frac{M_{t}+B_{t}}{M_{t+1}+B_{t+1}}\right)(1+\mu)=\frac{y-d_{t+1}}{c_{t}}
\end{aligned}
$$

Equations (14) and (15), together with the market-clearing condition

$$
d_{t}+D_{t}=y=c_{t}+C_{t}
$$

determine the (stationary) equilibrium values of $\left(c_{t}, d_{t}, C_{t}, D_{t}\right)$. Clearing of the market for outside money requires that the demand for outside money as a settlement medium equal its supply, i.e., that

$$
M_{t}=\omega h_{t}=\omega\left(M_{t}+B_{t}\right) \Rightarrow M_{t} / B_{t}=\omega /(1-\omega)
$$


Consistency of equilibrium thus requires that the money-bond ratio in (19) be identical to that implied by the present-value budget balance condition (4), i.e., that

$$
\frac{r-\mu}{\mu}=\frac{\omega}{1+\omega} \Leftrightarrow \omega=\frac{r-\mu}{r}
$$

\section{Properties of the no-float equilibrium}

Inspection of equilibrium conditions (16), (17), and (18) reveals that the equilibrium values of $\left(c_{t}, d_{t}, C_{t}, D_{t}\right)$ are unaffected by the growth rate of the money stock $\mu$, i.e., money is superneutral. The equilibrium allocation in this case is also efficient in the sense that it solves the "golden-rule" social planner's problem of maximizing a populationweighted sum of utilities in steady state, subject to resource constraints (18). This problem has first-order condition

$$
u_{C} / u_{D}=v_{c} / v_{d}
$$

which is implied by equilibrium conditions (16) and (17). ${ }^{13}$

\subsection{Equilibrium with float}

We now consider a version of the model where all young debtors buy goods in "remote" locations, i.e., in archipelagoes other than their own. Checks written at these remote locations are assumed to take one period to clear, so that debtors can collect interest on their deposits until their checks clear during the next period. We assume that these checks written at $t$ are cleared and settled in the first stage of period $t+1$. As before, a

\footnotetext{
${ }^{13}$ It should be emphasized that superneutrality of money and the optimality of competitive equilibrium are special-case results, which depend on the absence of a government deficit net-of-interest. In earlier versions of this paper, we analyzed cases where the government runs a positive deficit net-of-interest, and found that results concerning check float were not affected. For a general steady-state analysis of the welfare effects of inflationary monetary policy, see Mulligan and Sala-i-Martin (1997).
} 


\section{A General Equilibrium Analysis of Check Float}

fraction $\omega$ of these checks are settled by transfer of outside money. Checks written by creditors are cleared through the local clearinghouse and clear within the same period.

In this version of the model, the budget constraints for a representative debtor are

$$
\begin{aligned}
& y p_{t}=d_{t} p_{t}+h_{t} \\
& h_{t}\left(1+\phi_{t}\right)=c_{t} p_{t}^{*}
\end{aligned}
$$

A representative creditor has budget constraint

$$
y_{t} p_{t}^{*}=C_{t} p_{t}^{*}+l_{t+1}=C_{t} p_{t}^{*}+D_{t+1} p_{t+1}
$$

These budget constraints imply the following first-order conditions for the debtor and creditor, respectively:

$$
\begin{aligned}
& v_{c} / v_{d}=\left(p_{t}^{*} / p_{t}\right)\left(1 /\left(1+\phi_{t}\right)\right) \\
& u_{C} / u_{D}=p_{t}^{*} / p_{t+1}
\end{aligned}
$$

To solve for the equilibrium allocation, we adopt the same strategy as beforeimposing balance sheet identities and then solving for market-clearing conditions. The representative bank's balance sheet is given in Table 2 .

$$
<\text { Insert Table 2> }
$$

To obtain $p_{t}^{*}$, we note that the amount of the debtors' funds available for purchasing creditor goods must equal the value of the purchase, i.e., from Table 2 ,

$$
h_{t}\left(1+\phi_{t}\right)=l_{t+1}=M_{t+1}+B_{t+1}=c_{t} p_{t}^{*}
$$

which implies

$$
p_{t}^{*}=\frac{M_{t+1}+B_{t+1}}{c_{t}}
$$


Similarly, the value of the young debtors' goods purchased by the old creditors must equal the amount of deposits held by the old creditors, implying

$$
p_{t}=\frac{M_{t}+B_{t}}{y-d_{t}}
$$

Substituting the expressions for prices into first-order conditions (25) and (26), and exploiting the fact that $\phi_{t}=\mu$ we obtain

$$
\begin{aligned}
& \frac{v_{c}}{v_{d}}=\frac{p_{t}^{*}}{p_{t}\left(1+\phi_{t}\right)}=\left(\frac{M_{t+1}+B_{t+1}}{(1+\mu)\left(M_{t}+B_{t}\right)}\right)\left(\frac{y-d_{t}}{c_{t}}\right)=\frac{y-d_{t}}{c_{t}} \\
& \frac{u_{C}}{u_{D}}=\frac{p_{t}^{*}}{p_{t+1}}=\left(\frac{M_{t+1}+B_{t+1}}{c_{t}}\right)\left(\frac{y-d_{t+1}}{M_{t+1}+B_{t+1}}\right)=\frac{y-d_{t+1}}{c_{t}}
\end{aligned}
$$

Equations (30) and (31) are identical to equilibrium conditions (16) and (17) from the no-float model; hence they imply the same equilibrium allocation as in the no-float model. As was the case with the no-float model, in equilibrium money is superneutral and the equilibrium allocation is efficient. ${ }^{14}$ We summarize the results of this section as:

Result 1. If there are no clearing costs and the government budget is balanced net-ofinterest, then float has no effect on equilibrium allocations and the first-best (golden rule) allocation obtains with or without float.

Float fails to have any effect on equilibrium allocations because the income effect of transferring float from creditors to debtors is precisely offset by a substitution effect. The debtors use their float income to bid up the nominal price of each creditor good by $100 \mu$ percent. By contrast, the nominal prices of debtor goods are unaffected. Hence, the

\footnotetext{
${ }^{14}$ Freeman $(1996,113)$ derives a similar result.
} 


\section{A General Equilibrium Analysis of Check Float}

relative price of debtor goods rises by an amount just sufficient to offset the income effect of the float transfer.

The analysis above assumes that banks can only compete with one another by offering higher interest rates on deposits. Historically, this is a justifiable restriction since banks have been reluctant to charge explicit per check fees to their depositors, and have preferred to use minimum balance requirements and lower interest rates to cover costs associated with check payments. ${ }^{15}$ More recently, however, banks are covering these costs by charging fees. In Appendix A, we extend Result 1 to show that float does not affect equilibrium allocations in the case where banks can charge fees to cover the costs of settlement in outside funds.

\section{REMOTE DISBURSEMENT}

The analysis above implies a benign view of float. If delays occur in clearing and settling checks, then this analysis suggests that markets can adjust so that the costs associated with these delays are appropriately priced. Equilibrium allocations are unaffected by float and for the cases we analyze, are also efficient.

Is this Panglossian view of float applicable to the U.S. payment system? We think perhaps not. A potentially important friction results from the fact that lags in check clearing vary according to the distance between the paying bank and the collecting bank, yet the costs associated with such varying delays are not always priced at the point of sale. Wells (1996) notes that in business-to-business payments, the effects of float are often subject to negotiation and may be internalized via private contracts. Such negotiation is 


\section{A General Equilibrium Analysis of Check Float}

rare when payments involve consumers, however, perhaps due to the fact that the payments involved are often too small or infrequent to offset contracting costs. Consider, for example, the case of an electric utility. When the utility agrees to provide a large industrial customer with electricity, it is worthwhile for both the utility and the customer to precisely negotiate terms of payment. On the other hand, it would be extremely impractical for the same utility to negotiate a customized contract with each of residential or small business customers. Instead, these customers are offered a standardized contract without contingencies for payment float.

Our model can capture the effect of unpriced differential clearing times if we divide each generation of debtors into two classes, according to the time it takes their checks to clear. For analytical convenience, we employ the version of the model without fees. The first class of debtors, known as "local debtors," always journeys when young to islands relatively close to their home market. Hence checks written by these debtors at time $t$ will clear during period $t$. The second class of debtors, known as "remote debtors," always journeys when young to islands in a remote market. Checks written by young debtors to creditors on these remote islands always take two periods to clear. ${ }^{16}$

If a creditor does not price the float, this gives an advantage to remote debtors. The budget set of local debtors is constrained by the no-float equation (6), while that of remote debtors is constrained by the float equations (22) and (23). The typical creditor sells to both remote and local debtors, at the same price. The creditor's budget constraint is given by

\footnotetext{
${ }^{15}$ See Committee on the Federal Reserve in the Payments Mechanism (1998, 11).
} 


$$
y p_{t}^{*} \psi_{t}=C_{t} p_{t}^{*} \psi_{t}+D_{t+1} p_{t+1}
$$

where $\psi_{t}$ represents the average time $t+1$ value of payments received at time $t$. The creditor's budget constraint says that the time $t+1$ value of the creditors' goods sold in period $t$ equals the value of goods purchased in period $t$. In symmetric equilibrium, the creditor sells $\lambda c_{t}$ to local debtors and $(1-\lambda) c_{t}^{\prime}$ to remote debtors, where $\lambda$ is the proportion of local debtors and primes denote consumption by remote debtors. Hence we have

$$
\psi_{t}=\frac{\lambda c_{t}\left(1+\phi_{t}\right)+(1-\lambda) c_{t}^{\prime}}{\lambda c_{t}+(1-\lambda) c_{t}^{\prime}}=\frac{\lambda c_{t}\left(1+\phi_{t}\right)+(1-\lambda) c_{t}^{\prime}}{y-C_{t}}
$$

Budget constraints (6), (22), (23), and (32) imply the following respective firstorder conditions for local debtors, remote debtors, and creditors.

$$
\begin{aligned}
& v_{c} / v_{d}=p_{t}^{*} / p_{t} \\
& v_{c}^{\prime} / v_{d}^{\prime}=\left(p_{t}^{*} / p_{t}\right)\left(1 /\left(1+\phi_{t}\right)\right) \\
& u_{C} / u_{D}=\left(p_{t+1}^{*} / p_{t}\right) \psi_{t}
\end{aligned}
$$

Market-clearing conditions are given by

$$
\begin{aligned}
& p_{t}^{*}=\frac{M_{t+1}+B_{t+1}}{\lambda c_{t}\left(1+\phi_{t}\right)+(1-\lambda) c_{t}^{\prime}} \\
& p_{t}=\frac{M_{t}+B_{t}}{y-\lambda d_{t}-(1-\lambda) d_{t}^{\prime}}
\end{aligned}
$$

Substituting the market-clearing conditions into the first-order conditions, we obtain the equilibrium relations

$$
\frac{v_{c}}{v_{d}}=\left(\frac{y-\underline{d}_{t}}{\underline{c}_{t}}\right)\left(\frac{1+\mu}{\psi_{t}}\right)
$$

\footnotetext{
${ }^{16}$ An alternative interpretation, suggested by the analysis of Lacker (1997), is that creditors are successful
} 


$$
\begin{aligned}
& \frac{v_{c}^{\prime}}{v_{d}^{\prime}}=\left(\frac{y-\underline{d}_{t}}{\underline{c}_{t}}\right)\left(\frac{1}{\psi_{t}}\right) \\
& \frac{u_{C}}{u_{D}}=\left(\frac{y-\underline{d}_{t+1}}{\underline{c}_{t}}\right)
\end{aligned}
$$

where $\underline{c}_{t}$ and $\underline{d}_{t}$ are weighted averages of debtor consumption of creditor and debtor goods, i.e.,

$$
\begin{aligned}
& \underline{c}_{t} \equiv \lambda c_{t}+(1-\lambda) c_{t}^{\prime} \\
& \underline{d}_{t} \equiv \lambda d_{t}+(1-\lambda) d_{t}^{\prime}
\end{aligned}
$$

Conditions (39)-(41) imply that the "remote disbursement" equilibrium allocation differs from the efficient allocation so long as $\lambda \in(0,1)$. Note that the equilibrium goes to the no-float equilibrium as the measure of local debtors $\lambda$ goes to one, and to the float equilibrium as $\lambda$ goes to zero. For $\lambda \in(0,1)$, however, the presence of unpriced float leads to an inefficient equilibrium. Formally, we have:

Result 2. Suppose that there are no clearing costs and that the government budget is balanced net-of-interest. If only a fraction $\lambda \in(0,1)$ of debtors have access to float, and float is not priced at the point of sale, an inefficient equilibrium results.

In general, the three equilibrium conditions (39)-(41) plus market-clearing are insufficient to determine equilibrium values of $\left(c_{t}, d_{t}, c_{t}^{\prime}, d_{t}^{\prime}, C_{t}, D_{t}\right)$. However, the remote disbursement equilibrium is easily solved for the special case where the utility of both creditors and debtors is time-separable and logarithmic, i.e.,

in accelerating presentment of checks to local debtors but not to remote debtors. This interpretation is discussed in more detail below. 


$$
\begin{aligned}
& v(c, d)=\log c+\log d \\
& u(C, D)=\log c+\log D
\end{aligned}
$$

For this case, the creditors' and debtors' demand for their respective endowment goods is price inelastic and given by $y / 2$. Using this fact, we obtain the following stationary equilibrium allocation:

$$
\begin{aligned}
& C=D=d=d^{\prime}=y / 2 \\
& c=\frac{y}{2(\lambda+(1-\lambda)(1+\mu))}<\frac{y}{2} \\
& c^{\prime}=\frac{(1+\mu) y}{2(\lambda+(1-\lambda)(1+\mu))}>\frac{y}{2}
\end{aligned}
$$

For positive rates of inflation $\mu$, it is easy to show that the consumption of remote debtors is increasing in $\lambda$. As was the case in Section 3 , for $0<\lambda<1$, remote debtors do not enjoy the full benefit of the float "transfer," but bid a portion of the benefits away in the form of higher prices for creditor gods. As the proportion of remote debtors grows and $\lambda$ falls to zero, the advantage of being a remote debtor is increasingly bid away until $c^{\prime}$ reaches its efficient value $\mathrm{y} / 2$.

We also note that for the log utility example, the average amount of check float in the economy is given by $(1-\lambda) c^{\prime} \mu$, which is the measure of remote debtors (=proportion of checks written by remote debtors), times the amount of their checks, times the interest received by the remote debtors while they are waiting for their checks to clear. This figure can be quite small if $\lambda$ is close to unity, yet the marginal benefit of float to "remote debtors" can be quite large. On the other hand, a small average amount of float implies small 


\section{A General Equilibrium Analysis of Check Float}

price distortions and hence, small losses in aggregate welfare that directly result from float-induced price distortions.

\section{CLEARING COSTS}

As noted above, a small average float amount implies that the welfare costs associated with float-induced price distortions are also small. However, Humphrey and Berger $(1990,51)$ and Lacker (1997a) point out another social cost associated with the use of check payment, which is the resource cost of activities designed to generate or reduce float. The setup above can be expanded to capture the effects of such costs.

Suppose, for example, that initially float is widespread in the economy and that banks compete for deposits only with interest rates paid on deposits, so that the model of Section 3.2 supplies. Suppose further that a new check-processing technology appears, so that at a real cost of $\gamma<y$ of the creditors' endowment goods per check, it is possible for banks to accelerate the presentment of the debtors' checks. Once the new technology is employed, debtors' checks clear during the same period they are written, and interest accrues to the creditors. Hence, the correct marginal equilibrium conditions for this case are just the no-float equilibrium conditions (16) and (17). However, the market-clearing condition (18) must now be adjusted for the loss of endowment goods associated with accelerated presentment. That is, under accelerated presentment, condition (18) would now become

$$
d_{t}+D_{t}=y=c_{t}+C_{t}+\gamma
$$

The equilibrium allocation implied by (16), (17) and (49) would be clearly be dominated by the optimal allocation resulting when there is neither float nor accelerated 


\section{A General Equilibrium Analysis of Check Float}

presentment (Section 3.2). That is, everyone would be better off if they could jointly agree not to accelerate presentment, and check float could be incorporated into market prices. Consider, however, the following result:

Result 3. Suppose that clearing is costless, except for accelerated presentment which incurs a cost of $\gamma$ per check. Then for the log utility case, accelerated presentment is sustainable as a noncooperative (Nash) equilibrium, as long (1) banks collecting payments must pay the costs of presentment, and (2) the interest rate is sufficiently high.

Proof: See Appendix B.

Intuitively, accelerated presentment can persist because it generates a private benefit (i.e., it favors payees who receive earlier use of their funds), which offsets its private cost. Accelerated presentment is inefficient, however, because it carries a positive social cost, but no social benefit.

There are a number of potential remedies for this inefficiency. The simplest remedy would be increased cooperation among affected parties. In the context of the model, it would be to the advantage of both debtors and creditors if the costs of accelerated presentment could be avoided by allowing the creditors to negotiate a higher price for their endowment goods "up front," in return for not accelerating presentment, rather than attempting to obtain a higher price through accelerated presentment. In the case of business-to-business payments, the size and regularity of payments may be sufficient to offset contracting costs. On the other hand, such cooperation would be hindered by the lesser size and regularity of payments involving consumers, suggesting that some policy intervention may also be necessary. 


\section{A General Equilibrium Analysis of Check Float}

\section{IMPLICATIONS}

The analysis above shows that there may be both less and more to the problem of float than has previously been thought. Result 1 shows that in general equilibrium, the market can offer a natural remedy to the float "problem" through price effects. That is, to the extent that the buyers in a particular market are beneficiaries of float, the market prices will adjust so as to offset the income effect afforded by float. In the case where float beneficiaries and non-beneficiaries are on the opposite sides of markets, then income effects are perfectly offset by price effects. Thus, float may not represent a transfer of real income. Depositors would give up nothing in terms of their real purchasing power, if they were to agree to switch en masse from a form of payment that allowed for float (such as checks) to a form of payment that did not (such as $\mathrm{ACH}$ ). Individual depositors, on the other hand, would lack an incentive to unilaterally give up their access to (unpriced) float.

Result 2 shows that if there is differential access to float by participants on the same side of a given market, and that if float is unpriced at the point of sale, then floatinduced distortions can result despite low average values of float as reported by Wells (1996). The last result suggests that float may remain a significant motive behind the continued use of checks. Specifically, if the marginal benefit of float is high for some group of check-writers, these check-writers have no incentive, either collectively or individually, to switch to a form of payment that denies them this float benefit (again, as long this benefit is not priced at the point of sale). Other check-writers who are not the beneficiaries of float would also not gain by switching payment systems, unless the checkwriters who are generating the float were also to change payment systems. This view is 


\section{A General Equilibrium Analysis of Check Float}

more in keeping with the "market-failure" characterization of check float advanced by Humphrey and Berger (1990).

Result 3 shows that there can be another inefficiency associated with check float, which results from costly attempts to "win the float game" by accelerating the presentment of checks. Since, from Result 1, there is no corresponding social gain, an inefficient outcome can result. As is the case with Result 1, there is no incentive for depositors to unilaterally switch to new, float-free forms of payment.

What sort of policies might correct the two sources of inefficiency described above? An example of a successful policy for mitigating the effects of check float can be found in Canada (see Bank for International Settlements 1993, 61). There, banks receiving a check drawn on another bank at period $t$, but unable to collect until $t+1$, are retroactively credited with funds as of date $t$. In other words, any differences in the value of payments induced by delays in clearing are offset by means of adjustments in the settlement process. These "as-of" adjustments automatically reallocate all gains from float to the collecting bank, rendering both remote disbursement and accelerated presentment pointless, abstracting from concerns about credit risk and fraud.

A reasonable question to ask is why a policy of this type has not been implemented in the U.S. case. A superficial response would be that the U.S. banking system is larger and more complex than Canada's, so that implementation of a major change in check-clearing rules would require the cooperation and agreement of a larger number of banks (and their depositors). However, if such a policy were really Pareto-improving, we would expect it to be put in place eventually. 


\section{A General Equilibrium Analysis of Check Float}

A more likely explanation, in our view, is that some depositors are able to successfully exploit the fact that for many types of payment, float is unpriced. As in the model of Section 4, this leads to welfare loss via a distortion, but also to a net gain for those depositors who are able to successfully exploit the system. This could occur despite the costly efforts of their payees to accelerate presentment and deny them the benefit of float. Hence a truly Pareto-improving policy would require both the elimination of float and the compensation of "float beneficiaries" for the loss of their float-derived income.

Finally, we should caution that the analysis above is not meant to imply that float is the only possible explanation for the continued use of checks. Other contributing factors that have been suggested include the convenience associated with check payment, and the high initial costs with associated with moving from paper-based to electronic payments. More detailed empirical analysis is clearly needed to sort out the relative magnitudes of these effects. 


\section{A General Equilibrium Analysis of Check Float}

\section{Appendix A: Effects of Float under Fee Competition}

In the equilibria of Section 3, banks must pay an inflation tax. One way of deriving this tax is to compare the time $t$ (end-of-period) market value of a bank's assets to the present value of its time $t+1$ assets, discounted by the interest rate on bonds. Calculating the difference between the two yields an inflation tax of

$$
M_{t}+B_{t}-\left(1+r_{t}\right)^{-1}\left(M_{t+1}+B_{t+1}\right)=\frac{r_{t} \omega}{1+r_{t}}\left(M_{t}+B_{t}\right)
$$

In the no-float equilibrium of section 3 , this tax is nominally borne by the creditors in the form of lower interest payments on their deposits. Since the tax results from actions undertaken by debtors, i.e., writing checks at remote locations, a possible response to this situation on the part of banks might be to charge fees to debtors for the use of their checking accounts. All debtors are charged the same fee, since there is no way ex ante to tell which debtors' checks will require settlement with outside money, and imposing differential fees on debtors ex post would amount to nonpar banking.

Fee competition without float

Suppose that there is no float and that banks charge fees equal to $\alpha_{t} h_{t}$ on a debtors' checking account having balance $h_{t}$. Then the time $t$ budget constraint of a typical bank (aggregating across all stages within the period) is given by

$$
B_{t}+M_{t}+p_{t} e_{t}+\left(1-\phi_{t-1}\right) l_{t-1}+\left(1-\alpha_{t}\right) h_{t}=\left(1+r_{t-1}\right) B_{t-1}+M_{t-1}+l_{t}+h_{t}
$$

where uses of funds are displayed on the left and sources of funds are displayed on the right. Banks also face a settlement constraint

$$
M_{t}=\omega h_{t}
$$




\section{A General Equilibrium Analysis of Check Float}

If we substitute (52) into the bank's budget constraint (51), and suppose that the bank discounts its profits at the steady-state real rate of interest so that its discount factor is given by $\beta=(1+\mu) /(1+r)$, then the bank's objective becomes (in steady state)

$$
\sum_{t=0}^{\infty}(1+r)^{-t}\left((1+r) B_{t-1}-B_{t}-\left(1+\phi_{t-1}\right) l_{t-1}+l_{t}-\omega\left(h_{t}-h_{t-1}\right)+\alpha h_{t}\right)
$$

Differentiating (35) with respect to $l_{t}$ and $h_{t}$, and solving we obtain

$$
\begin{aligned}
& \phi_{t}=r \\
& \alpha_{t}=\frac{\omega r}{1+r}=\frac{r-\mu}{1+r}
\end{aligned}
$$

Conditions (36) and (37) imply that creditors are paid the full return on the bank's bond portfolio $r$, while debtors bear the inflation tax associated with settlement in outside money. These conditions also imply that the bank's balance sheet (see Table 1) cannot balance at all stages during a given period. Specifically, the bank cannot pay the interest rate $r$ on creditors' deposits equal to the sum of its outside assets $\left(M_{t}+B_{t}\right)$, and also balance its books at both stage 1 and stage 3 of each period. If we adopt the interpretation that a "period" consists of a single trading day, then it is reasonable to require that the bank's books balance overnight, i.e., at stage 3 , so that $l_{t}=M_{t}+B_{t}=h_{t}$, as in equations (11) and (12). The debtor's budget constraint (6) is replaced by

$$
\left(1-\alpha_{t}\right)\left(y-d_{t}\right) p_{t}=h_{t}=c_{t} p_{t}^{*}
$$

The debtor's first-order condition (7) becomes

$$
\frac{v_{c}}{v_{d}}=\frac{p_{t}^{*}}{p_{t}\left(1-\alpha_{t}\right)}
$$


Substituting (12) into the debtor's budget constraint (56), we obtain the market clearing condition for the debtor good (cf. equation (14))

$$
p_{t}=\frac{M_{t}+B_{t}}{\left(1-\alpha_{t}\right)\left(y-d_{t}\right)}
$$

Since creditors do not pay fees, the creditor's first-order condition (10) and the marketclearing condition for the creditor good (15) are unchanged. Substituting the marketclearing conditions (15) and (58) into first-order conditions (10) and (57), using the fact that $\phi_{t}=r$, we obtain

$$
\begin{aligned}
\frac{v_{c}}{v_{d}} & =\frac{p_{t}^{*}}{\left(1-\alpha_{t}\right) p_{t}}=\left(\frac{M_{t}+B_{t}}{c_{t}}\right)\left(\frac{\left(1-\alpha_{t}\right)\left(y-d_{t}\right)}{\left(1-\alpha_{t}\right)\left(M_{t}+B_{t}\right)}\right)=\frac{y-d_{t}}{c_{t}} \\
\frac{u_{C}}{u_{D}} & =\frac{p_{t}^{*}}{p_{t+1}}\left(1+\phi_{t}\right)=\left(\frac{M_{t}+B_{t}}{c_{t}}\right)\left(\frac{\left(1-\alpha_{t+1}\right)\left(y-d_{t+1}\right)}{M_{t+1}+B_{t+1}}\right)(1+r) \\
& =\left(\frac{y-d_{t+1}}{c_{t}}\right)\left(\frac{\left(M_{t}+B_{t}\right)\left(1-\alpha_{t+1}\right)(1+r)}{\left(M_{t}+B_{t}\right)(1+\mu)}\right)=\frac{y-d_{t+1}}{c_{t}}
\end{aligned}
$$

where the last equality follows from the fact that $1-\alpha_{t}=(1+\mu) /(1+r)$. Equilibrium conditions (59) and (60) are the same as (16) and (17) in Section 3, hence the equilibrium allocation remains the same. Here, two income effects - the charging of fees to debtors and paying higher interest rates to creditors - are offset by a substitution effect. Relative to the no-fees case, the money price of debtor goods increases by the real interest rate, compensating debtors for their loss of income from payment bank fees, and offsetting the creditors' gain in interest income. 
Fee competition with float

Suppose now that debtors are charged fees and bear the inflation tax as in the previous section, but that their checks take a period to clear, as in section 3.2. The bank's budget constraint now becomes

$$
B_{t}+M_{t}+p_{t} e_{t}+\left(1-\phi_{t-1}\right) l_{t-1}+\left(1-\alpha_{t}\right)\left(1-\phi_{t-1}\right) h_{t-1}=\left(1+r_{t-1}\right) B_{t-1}+M_{t-1}+l_{t}+h_{t}
$$

Solving the bank's optimization problem again yields conditions (54) and (55). Since the bank charges fees $\alpha h_{t}$, the debtor's time $t$ budget constraint (22) is replaced by (56).

First-order condition (25) becomes

$$
\frac{v_{c}}{v_{d}}=\frac{p_{t}^{*}}{p_{t}\left(1-\alpha_{t}\right)\left(1+\phi_{t}\right)}
$$

The bank's end-of-period balance sheet requires

$$
h_{t}=M_{t}+B_{t}
$$

Since the time $t$ value of the funds expended by the debtors in period $t$ equals the value of the funds received by creditors in period $t+1$, we have

$$
\left(1+\phi_{t}\right) h_{t}=l_{t+1}
$$

Conditions (43) and (44), along with the budget constraints (23) and (56), imply the following market clearing conditions

$$
\begin{aligned}
& p_{t}=\frac{\left(M_{t-1}+B_{t-1}\right)\left(1+\phi_{t-1}\right)}{y-d_{t}} \\
& p_{t}^{*}=\frac{\left(M_{t}+B_{t}\right)\left(1+\phi_{t}\right)}{c_{t}}
\end{aligned}
$$


Substitute market-clearing conditions (65) and (66) in first-order conditions (26) and (62), and use the facts that $\phi_{t}=r$ and $\left(1-\alpha_{t}\right)=(1+\mu) /(1+r)$ to obtain the equilibrium conditions

$$
\begin{aligned}
& \frac{v_{c}}{v_{d}}=\frac{p_{t}^{*}}{p_{t}\left(1-\alpha_{t}\right)\left(1+\phi_{t}\right)}=\left(\frac{\left(M_{t}+B_{t}\right)(1+r)}{c_{t}}\right)\left(\frac{y-d_{t}}{\left(M_{t-1}+B_{t-1}\right)(1+r)^{2}(1-\alpha)}\right)=\frac{y-d_{t}}{c_{t}} \\
& \frac{u_{C}}{u_{D}}=\frac{p_{t}^{*}}{p_{t+1}}=\left(\frac{\left(M_{t}+B_{t}\right)(1+r)}{c_{t}}\right)\left(\frac{y-d_{t+1}}{\left(M_{t}+B_{t}\right)(1+r)}\right)=\frac{y-d_{t+1}}{c_{t}}
\end{aligned}
$$

Once again equilibrium allocations are unchanged. Relative to the fee-competition, nofloat case, debtors' additional interest income is offset by an increase in the price of creditor goods. Also, comparing the present case to the case with float but without fee competition (cf. price equations (28)-(29) and (65)-(66)), shows that allowing banks to compete by charging fees increases the nominal income of both debtors and creditors, but does not change the relative price of their endowment goods. 


\section{Appendix B: Proof of Result 3}

We first consider the case where creditors take advantage of accelerated presentment. In this case, appropriate equilibrium conditions are given by equations (16), (17), and (68). In the log-utility case (see Section 4 above), we can solve these equations for the creditors' equilibrium consumption of debtors' goods and creditors' goods, to obtain

$$
\begin{aligned}
& D=\frac{y}{2} \\
& C=\frac{y-\gamma}{2}
\end{aligned}
$$

In this case, the creditors' utility is therefore given by

$$
u(C, D)=\log y+\log (y-\gamma)-2 \log 2
$$

Suppose now that a creditor decides to deviate from this equilibrium by not taking advantage of accelerated presentment. The time $t$-generation creditor does not have to pay the cost of accelerated presentment but loses interest on debtor payments. If all other creditors continue to use accelerated presentment, then the deviating creditor's optimization problem would be to maximize utility subject to budget constraint from the "float case" (24), but where the equilibrium prices of creditor and debtor goods are determined by substituting the equilibrium quantities from (69) and (70) into the no-float price equations (14) and (15). Solving for the consumption of the deviating creditor we obtain

$$
\begin{aligned}
& D=\frac{y^{2}}{(y-\gamma)(1+\mu)} \\
& C=\frac{y}{2}
\end{aligned}
$$

The utility of the deviating creditor is given by 


$$
\begin{array}{r}
\text { A General Equilibrium Analysis of Check Float } \\
u(C, D)=3 \log y-\log (y-\gamma)-\log (1+\mu)-2 \log 2
\end{array}
$$

For sufficiently large $\mu$, i.e., a sufficiently high interest rate, the RHS of (71) exceeds the RHS of (74), implying creditors would have no incentive to deviate from the accelerated presentment equilibrium.

Q.E.D. 


\section{References}

Bank for International Settlements. Statistics on Payment Systems in the Group of Ten Countries. Basle, 1997.

Bank for International Settlements. Payment Systems in the Group of Ten Countries. Basle, 1993.

Bullard, James and Steven Russell. "How Costly is Sustained Low Inflation for the U.S. Economy?” Manuscript, Federal Reserve Bank of St. Louis, April 1997.

Committee on the Federal Reserve in the Payments System. "The Federal Reserve in the Payments Mechanism.” Mimeo, January 1998.

Duprey, James N. and Clarence W. Nelson. “A Visible Hand: The Fed's Involvement in the Check Payments System.” Federal Reserve Bank of Minneapolis Quarterly Review 10 (Spring 1986): 18-29.

Emmons, William R. "Interbank Netting Agreements and the Distribution of Bank Default Risk.” Federal Reserve Bank of St. Louis Working Paper 95-016A, 1995.

Espinosa, Marco and Steven Russell. "Conventional Monetary-Policy Wisdom in the Diamond Model.” Manuscript, December 1996.

Flatraaker, Dag-Inge and Pål Erik Robinson, "Income, Costs and Pricing in the Payment System.” Norges Bank Economic Bulletin (March 1995): 321-32.

Freeman, Scott. "Clearinghouse Banks and Banknote Over-Issue." Journal of Monetary Economics 38 (July 1996a): 101-15.

Freeman, Scott. "The Payments System, Liquidity, and Rediscounting." American Economic Review 86 (1996b): 1126-38.

Green, Edward J. "Money and Debt in the Structure of Payments." Bank of Japan Monetary and Economic Studies 15 (1997): 63-87.

Humphrey, David B. and Allen N. Berger. "Market Failure and Resource Use: Economic Incentives to Use Different Payment Instruments." In The U.S. Payment System: Efficiency, Risk and the Role of the Federal Reserve: Proceedings of a Symposium on the U.S. Payment system Sponsored by the Federal Reserve Bank of Richmond, ed. David B. Humphrey, pp.45-86. Boston: Kluwer Academic Publishers, 1990.

Humphrey, David B., Lawrence B. Pulley, and Jukka M. Vesala. "Cash, Paper, and Electronic Payments: A Cross-Country Analysis." Journal of Money, Credit, and Banking, 28 (November 1996): 914-39. 
Kahn, Charles M. and William Roberds. "Payments System Settlement and Bank Incentives.” Review of Financial Studies, 11 (1998): 845-70.

Lacker, Jeffrey M. "The Check Float Puzzle.” Federal Reserve Bank of Richmond Economic Quarterly 83 (Summer 1997a): 1-25.

Lacker, Jeffrey M. "Clearing, Settlement, and Monetary Policy." Journal of Monetary Economics 40 (1997b): 347-81.

Lucas, Robert E. "Equilibrium in a Pure Currency Economy." Economic Inquiry 18 (April 1980): 203-20.

Mulligan, Casey B. and Xavier X. Sala-i-Martin. “The Optimum Quantity of Money: Theory and Evidence." Journal of Money, Credit, and Banking 29 (November 1997, Part 2): 687-715.

Sargent, Thomas J. Macroeconomic Theory. $2^{\text {nd }}$ Ed., Orlando: Academic Press, 1987.

Wells, Kirsten E. “Are Checks Overused?" Federal Reserve Bank of Minneapolis Quarterly Review 20 (Fall 1996): 2-12. 
Table 1: Representative Bank's Balance Sheet

(No-Float Case)

Stage 1:

\begin{tabular}{|l|l|}
\hline Assets & Liabilities + NW \\
\hline Bonds $B_{t}$ & $\left(1+\phi_{t-1}\right) l_{t-1}$ deposits of old creditors \\
Outside money $M_{t}$ & $\mathrm{NW}(=0$ in equilibrium $)$ \\
\hline
\end{tabular}

Stage 2:

\begin{tabular}{|l|l|}
\hline Assets & Liabilities + NW \\
\hline Bonds $B_{t}$ & $h_{t}$ deposits of young debtors \\
Outside money $M_{t}$ & $\left(1+\phi_{t-1}\right) l_{t-1}$ deposits of old creditors \\
Goods of young debtors worth $p_{t}\left(y-d_{t}\right)$ & $\mathrm{NW}(=0$ in equilibrium $)$ \\
\hline
\end{tabular}

Stage 3:

\begin{tabular}{|l|l|}
\hline Assets & Liabilities + NW \\
\hline Bonds $B_{t}$ & $\begin{array}{l}l_{t} \text { deposits of young creditors } \\
\text { Outside money } M_{t}\end{array}$ \\
NW ( $=0$ in equilibrium $)$
\end{tabular}


Table 2: Representative Bank's Balance Sheet

(Float Case)

Stage 1:

\begin{tabular}{|l|l|}
\hline Assets & Liabilities + NW \\
\hline Bonds $B_{t}$ & $l_{t}=\left(1+\phi_{t-1}\right) h_{t-1}$ deposits of old creditors \\
Outside money $M_{t}$ & $\mathrm{NW}(=0$ in equilibrium $)$ \\
\hline
\end{tabular}

Stage 2:

\begin{tabular}{|l|l|}
\hline Assets & Liabilities + NW \\
\hline Bonds $B_{t}$ & $h_{t}$ deposits of young debtors \\
Outside money $M_{t}$ & $l_{t}$ deposits of old creditors \\
Goods of young debtors worth $p_{t}\left(y-d_{t}\right)$ & $\mathrm{NW}(=0$ in equilibrium $)$ \\
\hline
\end{tabular}

Stage 3:

\begin{tabular}{|l|l|}
\hline Assets & Liabilities + NW \\
\hline Bonds $B_{t}$ & $\begin{array}{l}h_{t} \text { deposits of young debtors } \\
\text { Outside money } M_{t}\end{array}$ \\
NW (=0 in equilibrium $)$
\end{tabular}




\section{Figure 1: Movement of Agents in the Model}

\section{Banking Market 1}

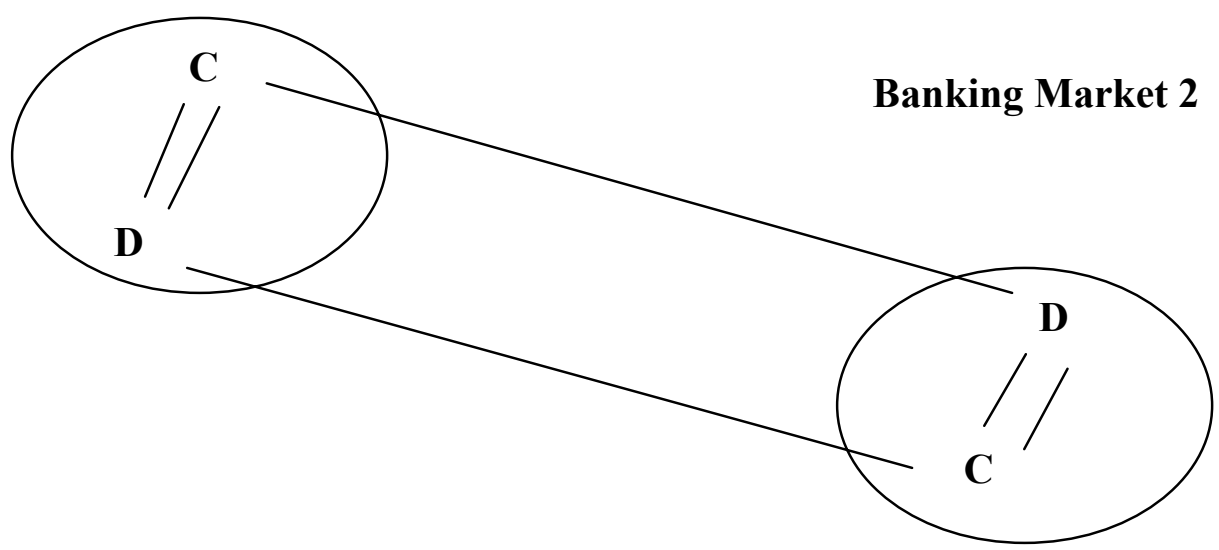

